\title{
RdDM pathway components differentially modulate Tobamovirus symptom development
}

\section{Melisa Leone, Diego Zavallo, Andrea Venturuzzi \& Sebastián Asurmendi}

\section{Plant Molecular Biology}

An International Journal on Molecular

Biology, Molecular Genetics and

Biochemistry

ISSN 0167-4412

Plant Mol Biol

DOI 10.1007/s11103-020-01051-6 
Your article is protected by copyright and all rights are held exclusively by Springer Nature B.V.. This e-offprint is for personal use only and shall not be self-archived in electronic repositories. If you wish to self-archive your article, please use the accepted manuscript version for posting on your own website. You may further deposit the accepted manuscript version in any repository, provided it is only made publicly available $\mathbf{1 2}$ months after official publication or later and provided acknowledgement is given to the original source of publication and a link is inserted to the published article on Springer's website. The link must be accompanied by the following text: "The final publication is available at link.springer.com". 


\title{
RdDM pathway components differentially modulate Tobamovirus symptom development
}

\author{
Melisa Leone $e^{1,2} \mathbb{D} \cdot$ Diego Zavallo $^{1} \mathbb{D} \cdot$ Andrea Venturuzzi $^{1}\left(\mathbb{D} \cdot\right.$ Sebastián Asurmendi $^{1} \mathbb{D}$
}

Received: 8 March 2020 / Accepted: 11 August 2020

(c) Springer Nature B.V. 2020

\begin{abstract}
Key Message The crop yield losses induced by phytoviruses are mainly associated with the symptoms of the disease. DNA modifications as methylation can modulate the information coded by the sequence, process named epigenetics. Viral infection can change the expression patterns of different genes linked to defenses and symptoms. This work represents the initial step to expose the role of epigenetic process, in the production of symptoms associated with plants-virus interactions.

Abstract Small RNAs (sRNAs) are important molecules for gene regulation in plants and play an essential role in plantpathogen interactions. Researchers have evaluated the relationship between viral infections as well as the endogenous accumulation of sRNAs and the transcriptional changes associated with the production of symptoms, but little is known about a possible direct role of epigenetics, mediated by 24-nt sRNAs, in the induction of these symptoms. Using different RNA directed DNA methylation (RdDM) pathway mutants and a triple demethylase mutant; here we demonstrate that the disruption of RdDM pathway during viral infection produce alterations in the plant transcriptome and in consequence changes in plant symptoms. This study represents the initial step in exposing that DNA methylation directed by endogenous sRNAs has an important role, uncoupled to defense, in the production of symptoms associated with plant-virus interactions.
\end{abstract}

Keywords Epigenetics $\cdot$ Immunity $\cdot \operatorname{RdDM} \cdot \operatorname{sRNAs} \cdot$ Symptoms $\cdot$ Virus

\section{Introduction}

Diseases associated with viruses produce diverse symptoms commonly associated to crop losses. Phytoviruses induce different metabolic and physiological alterations that in many cases result in symptomatic disease phenotypes. Viral infections can cause growth retardation, leaf mosaic, yellowing, necrosis and various developmental disorders (Wang

Electronic supplementary material The online version of this article (https://doi.org/10.1007/s11103-020-01051-6) contains supplementary material, which is available to authorized users.

Sebastián Asurmendi

asurmendi.sebastian@inta.gob.ar

1 Instituto de Agrobiotecnología y Biología Molecular (IABIMO), Instituto Nacional de Tecnología Agropecuaria (INTA), Consejo Nacional de Investigaciones Científicas y Técnicas (CONICET), De Los Reseros y N. Repetto S/N, Hurlingham, B1686IGC Buenos Aires, Argentina

2 Agencia Nacional de Promoción Científica y Tecnológica (ANPCyT), Buenos Aires, Argentina et al. 2012). For this reason, understanding the molecular bases associated to symptomatology production is essential to generate new biotechnological strategies in search of resistant plants (Nicaise 2014).

The Tobamoviruses genus includes 37 species of viruses known to infect many crops, such as potatoes, tomatoes, cucumbers, tobacco, among others. Tobacco mosaic virus $\mathrm{Cg}$ (TMV-Cg) and Oilseed rape mosaic virus (ORMV) are two strains (with more than $90 \%$ genome sequence homology) of the Tobamovirus genus that infect Arabidopsis thaliana plants producing differential symptomatology (Aguilar et al. 1996; Zavallo et al. 2015). Briefly, during infection, the virus first enters the plant after mechanically damaging the cell wall and plasma membrane. Soon after, Capside Protein (CP) begins to be disengaged from the virion and, then, the first protein translated directly from the genome, the replicase, initiates the replication of the viral genome (Shaw, 1999). The cell to cell movement of the virus depends on viral Movement Protein (MP), although other viral proteins are responsible for this process in some other species. 
An efficient viral infection requires the interaction between viral proteins and host cell factors that causes a manipulation of metabolic pathways and coordinates the biochemical interactions promoting infection. The recognition of viral double stranded RNA (dsRNA) molecules by the plant defense system leads to the induction of RNA silencing (Niehl et al. 2016; Niehl and Heinlein 2019). However, many plant viruses evade this silencing process and induce viral counter defense (Vance and Vaucheret 2001; Conti et al. 2017a). Finally, as a result of the mentioned viralplant interaction, systemic symptoms appear. The causes of symptom induction are diverse and, moreover, many depend on the interference with the normal physiological processes of plants occurring upon defense response (Pallas and García 2011).

In addition, viral infection is associated with global transcriptome reprogramming and changes in hormonal pathways as well as with the increase of the accumulation of metabolites and antioxidant compounds that produce disease phenotypes (Bazzini et al. 2011; Westwood et al. 2013; Dastogeer et al. 2018). For instance, chlorosis is a characteristic symptom widely correlated with modifications and global repression of photosynthetic genes induced by viruses as a result of changes in the quantity, size or structural alterations of chloroplasts (Bilgin et al. 2010; Li et al. 2016; Bhattacharyya and Chakraborty 2018).

RNA silencing is a transcriptome regulation mechanism that uses small RNAs (sRNAs) as guides that act by cytosine DNA methylation via Transcriptional Gene Silencing (TGS) or post-transcriptionally by cleavage of RNA targets (PTGS) (Castel and Martienssen 2013; Borges and Martienssen 2015; Kørner et al. 2018) to regulate gene expression, modify chromatin topology or defend against viral infections (Baulcombe 2004). In this context, the RNA-directed DNA methylation (RdDM) pathway is a methylation mechanism that can occur in different cytosine sequence contexts directed mainly by 24-nt sRNAs (Law and Jacobsen 2010; Gallego-Bartolomé et al. 2019). The canonical RdDM pathway requires the action of two RNA polymerases (Pol IV-Pol V). RNA polymerase IV generate single strand RNAs and RNA-dependent RNA polymerase 2 (RDR2) forms the dsDNAs that are processed by Dicer like 3 (DCL3) to produce 24-nt sRNAs. Then, 24-nt sRNAs are loaded into argonaute 4 (AGO4) and this combined structure interacts with Pol V produced transcript to finally, lead the methylation of DNA target sequences through the interaction with a methyltransferase (He et al. 2014; Xie and Yu 2015).

DNA methylation is an epigenetic phenomenon that plays a key regulatory role in many biological processes, including transposon silencing and responses to biotic and abiotic stresses. Usually, methylation of promoters, transposons or repeat sequences is linked to TGS effects, whereas gene-body methylation (in some cases), seems to be positively correlated with active transcription (To et al. 2015; Liang et al. 2019). The insertion of transposons near or into genes can alter gene expression, which in some cases can produce phenotypic consequences (Bewick and Schmitz 2017). For example, a successful heat response in Arabidopsis depends on the integrity of epigenetic pathways and the evidence indicate that heat-dependent gene expression is influenced by transposon sequences located near genes linked to heat stress (Popova et al. 2013). Achour et al. (2019) showed that prolonged low temperature exposure promotes the activation of genes involved in the regulation of DNA methylation. Thus, this transcriptional activation together with the extensive change of methylation in transposons along the genome shows the importance of hypermethylation of TEs in response to abiotic stress.

DNA methylation also plays an important role in defense response. In recent years, several studies have recognized the link between epigenetics and immunity. For instance, defective Pol V mutants show greater resistance to disease against bacterial pathogen Pseudomonas syringae (López et al. 2011). In other study, demethylation activated Xa21, a gene that confers resistance to bacterium Xanthomonas oryzae $p v$. in rice and, furthermore, the progeny inherited both hypomethylation and the acquired phenotype (Akimoto et al. 2007). In addition, methylation of pericentromeric TEs could affect the expression of PRR/NLR genes (Cambiagno et al. 2018). In recent years, researchers have published several studies about the effects of DNA methylation on antiviral defense. The TRV and Cucumber Mottled Green Mosaic Virus (CGMMV) infection in Arabidopsis and watermelon, respectively, produces a key component of the RdDM machinery deregulation, thus evidencing an important role of methylation in antiviral defense (Diezma-Navas et al. 2019; Sun et al. 2019). Another study revealed a novel regulatory mechanism, whereby Cotton Leaf Curl Multan virus (CLCu$\mathrm{MuV}$ ) $\mathrm{C} 4$ protein suppresses TGS and PTGS mediated by SAMS (a central enzyme in the methyl cycle), which leads to an improved viral infection in the plant (Ismayil et al. 2018). Although the molecular mechanisms involved in the production of virus-induced symptoms have been widely studied, they are still poorly understood.

In this study, we assessed the role of epigenetics in the production of symptoms in Arabidopsis thaliana inoculated with two Tobamoviruses strains (ORMV AND TMV$\mathrm{Cg}$ ). We detected that viral infection modified the expression of genes mapped by differentially accumulated (DA) 24-nt sRNAs. The impact of this alteration is not directly linked to plant defense, although it affects the emergence of symptoms in an RdDM-dependent manner. Our findings reveal a possible role of DNA methylation in viral symptomatology. 


\section{Results}

Evidence has shown the important role of 24-nt sRNAs in plant immunity through Transcriptional Gene Silencing (TGS) (Huang et al. 2016). We performed a comparative sRNA-seq analysis between non-infected (mock inoculated) and infected plants with two Tobamoviruses (TMV-Cg and ORMV) to select genes mapped by 24-nt endogenous sRNAs at 4 dpi (Zavallo et al. 2015).

\section{Selection of a subset of genes with differential accumulation of sRNAs}

Original data were fully reanalyzed by means of a new tool. We used Shortstack software (Axtell 2013) to select genomic regions with differentially accumulated (DA) 24-nt sRNAs between treatments. This reanalysis allows an improved method of placement of multimapping reads based on weighted probabilities by the unique mapped reads (Johnson et al. 2016) (see more in Material and Method section). Then, we identified features of interest (genes, promoters or nearby transposons) associated with DA sRNAs. A 1.5 fold-change difference between treatments and a p-value below 0.001 were considered for the selection. Table 1 details the selected genes with 24-nt sRNAs mapped to promoter regions (GP), gene body (GB) or nearby transposons (TEs). Panel a) details differential genes selected by comparing each virus (TMV$\mathrm{Cg} / \mathrm{ORMV}$ ) with non-infected plants (MI), whereas panel b) shows the comparison between both viruses (ORMV vs TMV-Cg). A total of 87 genes associated to DA sRNAs clusters between treatments comparing infected versus the non-infected plants were detected (Table S1). Of these genes, $62 \%$ corresponded to genes mapped by sRNAs in gene promoter, $16 \%$ in gene body and $22 \%$ in genes located near TEs ( $2 \mathrm{~kb}$ each side) (Fig. 1a, upper left panel). Both viruses altered $23 \%$ of these genes in a similar way (shared genes group), the remaining $77 \%$, represent genes altered by a single treatment considering the sum of the genes altered by ORMV alone (38\%) and those altered by TMV-Cg alone (39\%) (unique genes group). In detail, 50\% from the total are genes with DA sRNAs in promoter regions that belongs to unique genes group, and $12 \%$ belonging to shared genes group. Genes mapped by DA sRNAs in gene body or gene-associated TEs showed $9 \%$ unique, $7 \%$ shared and $17 \%$ unique, $5 \%$ shared, respectively (Fig. 1a, bottom left panel). Additionally, 59 genes showed significant differences between viruses (ORMV vs TMV-Cg) treatment (Table S1). In this case, $49 \%$ consisted of genes mapped by sRNAs in gene promoter, $27 \%$ in gene body and $24 \%$ in TEs near genes (Fig. 1a, upper right panel).
To provide a global hint to the functions and pathways of selected genes, we performed a gene ontology analysis to compare overrepresented GO terms in each group of genes, shared or unique. Table S2 listed the three types of GO terms (CC, MF, and BP) in which DA sRNAs (infected vs mock comparison) genes are overrepresented divided in two sheets; shared group and unique group. The results show overrepresented GO terms for each set of genes. Interestingly, the GO terms in the shared genes group appear to be higher on the GO classification scale than the overrepresented ones in the unique genes modified by TMV-Cg or ORMV alone, it may be indicative of a central function for viral infection. Notably, the analyses show that some identified enriched GO terms are linked to processes expected to be altered by viral infection. For example, GO categories like regulation of timing of plant organ form (GO:0,090,709) that could be associated with the symptoms production; mRNA binding (GO:0,003,729); integral component of chloroplast outer (GO:0,031,359) are over-represented on the shared genes group. In unique genes group we highlight pathways related to chromatin-mediated maintenance of transcription (GO:0,048,096); chlorophyll(ide) $\mathrm{b}$ reductase activity (GO:0,034,256); formate dehydrogenase complex (GO:0,009,326) and chloroplast thylakoid membrane (GO:0,009,535).Fig. 1b-d show the distribution of 24-nt sRNAs in plants infected with TMV-Cg/ORMV and mock-inoculated plants in three different regions of the DNA (set of selected genes of Table 1), either in the promoter (Fig. 1b), in gene body (Fig. 1c) or/and in transposons near $(2 \mathrm{~Kb})$ non-coding regions (5-UTR and 3-UTR) (Fig. 1d). The infection with ORMV and TMV-Cg produced altered accumulation of 24-nt sRNAs in selected genes. Furthermore, in accordance with Zavallo et al. (2015), we confirmed that viral infection alters the profile of sRNAs in early times of infection. Importantly, viral infection alters to greater extent 24-nt sRNAs associated with TEs (Fig. 1d). We selected four genes close to TEs $(2 \mathrm{~kb})$ that were differentially accumulated by $24-n t$ sRNAs. Indeed, three of the TEs belonged to the RC/Helitron superfamily: ATREP 3, in the 3-UTR region of the AT2G26540 gene; ATREP1, 2-kb from the 5-UTR region of the AT5G42960 gene and ATREP10D, 1-kb from the 5-UTR region of AT5G42567 gene. Finally, AT9NMU1: DNA/MuDR superfamily located near the 3-UTR region of AT3G18830 gene. It is important to note that most of the selected genes (Table 1) have TEs nearby when considering a region larger than the $2 \mathrm{~kb}$ previously selected.

\section{Molecular analysis of the selected genes in wild type plants}

To assess whether the infection with two strains of Tobamovirus affects mRNA expression levels we performed 
Table 1 Subgroup of selected genes with differential accumulation of endogenous 24-nt sRNAs in Arabidopsis thaliana infected with two Tobamoviruses (TMV-Cg and ORMV) at $4 \mathrm{dpi}$

Virus vs Mock inoculated

\begin{tabular}{llll}
\hline Gene ID & sRNAs (p value) & $\log _{2}$ FC
\end{tabular}

(a) sRNAs with differences between ORMV and/or TMV-Cg versus mock-inoculated plants mapped to promoters, gene body or transposons of the selected genes

\begin{tabular}{|c|c|c|c|}
\hline \multicolumn{4}{|c|}{ Genes with 24 bp sRNAs in Gene Promoter (GP) } \\
\hline AT1G27820 (caflc) & 0.00022 & -1.5 & $O M$ \\
\hline AT2G05710 (aco3) & $3.96684 E-08$ & -3.2 & $T M$ \\
\hline AT4G18290 (kat2) & $2.3127 E-06$ & -1.9 & $T M$ \\
\hline AT1G51630 (msr2) & $1.14013 E-05$ & 3 & $O M$ \\
\hline \multicolumn{4}{|c|}{ Genes with 24 bp sRNAs in Gene Body (GB) } \\
\hline AT2G41100 (touch3) & 0.01 & 2.3 & $O M$ \\
\hline $\begin{array}{l}\text { AT5G20850 } \\
(\mathrm{rad51})\end{array}$ & 0.006 & 3.5 & $O M$ \\
\hline \multicolumn{4}{|l|}{ Genes with 24 bp sRNAs in TEs } \\
\hline $\begin{array}{l}\text { AT2G26540 } \\
\text { (hemd) AT2TE48795 }\end{array}$ & 0.0007 & 2.9 & $\mathrm{TM}$ \\
\hline AT5G42960 (oe24b) AT5TE62265 & $6.49 \mathrm{E}-09 / 5.58 \mathrm{E}-10$ & $5.4 / 6$ & $\mathrm{OM} / \mathrm{TM}$ \\
\hline $\begin{array}{l}\text { AT5G42567 } \\
(\text { ecal-3) }(\text { AT5TE61440) }\end{array}$ & 0.0009 & 2.3 & $O M$ \\
\hline \multicolumn{4}{|l|}{ ORMV vs TMV-Cg } \\
\hline Gene ID & & & $\log _{2} \mathrm{FC}$ \\
\hline
\end{tabular}

(b) sRNAs with differences between ORMV versus TMV-Cg in A. thaliana plants mapped to promoters, gene body or transposons of selected genes

Genes with 24 bp sRNAs in Gene Promoter (GP)

\begin{tabular}{lll} 
AT4G26600 (nop2b) & $4.3 \mathrm{E}-05$ & 2.6 \\
AT1G27820 (caflc) & $6.89 E-06$ & -1.9 \\
AT2G05710 (aco3) & $1.21 E-06$ & 2.9 \\
AT4G18290 (kat2) & $1.18838 E-05$ & 1.8 \\
AT1G51630 (msr2) & 0.0003 \\
Genes with 24 bp sRNAs in Gene Body (GB) & \\
AT3G45140 (lox2) & $2.98792 \mathrm{E}-05$ & 2.3 \\
AT3G50480 (hr4) & 0.0007 \\
AT1G29920 (cab2) & 0.0007 \\
AT2G41100 (touch3) & 0.001 \\
AT5G20850 (rad51) & 0.002 \\
Genes with 24 bp sRNAs in TEs & \\
AT3G18830 (pmt5) AT3TE27270 & $9,01113 \mathrm{E}-05$ & 3.4 \\
AT5G42567 & $3.90 E-06$ & -2.07 \\
(ecal-3) & & 5.7 \\
(AT5TE61440) & & 3.5 \\
\hline
\end{tabular}

The genes highlighted in italics appear in both tables

$M$ mock inoculated; $T M V$ - $C g(T)$ Tobacco Mosaic Virus; ORMV (O) Oilseed Rape Mosaic Virus

quantitative PCRs using specific primers for 14 genes. At 4dpi most of the selected genes showed increased mRNA levels in the infected plants, except AT3G45140 (lox2), which showed no significant differences (Fig. 2). Moreover, in wild type plants (Col-0), all genes mapped by 24-nt sRNAs within the gene promoter region showed higher levels of mRNA
(Fig. 2a), as a consequence of a viral infection. Importantly, a negative correlation was evident between sRNA accumulation and transcription levels in most of promoter mapped genes considering infected versus mock inoculated plants (i.e. a decrease of sRNA amount and an increase of mRNA levels in the infected plants) (Table 1a; Fig. 2a). 


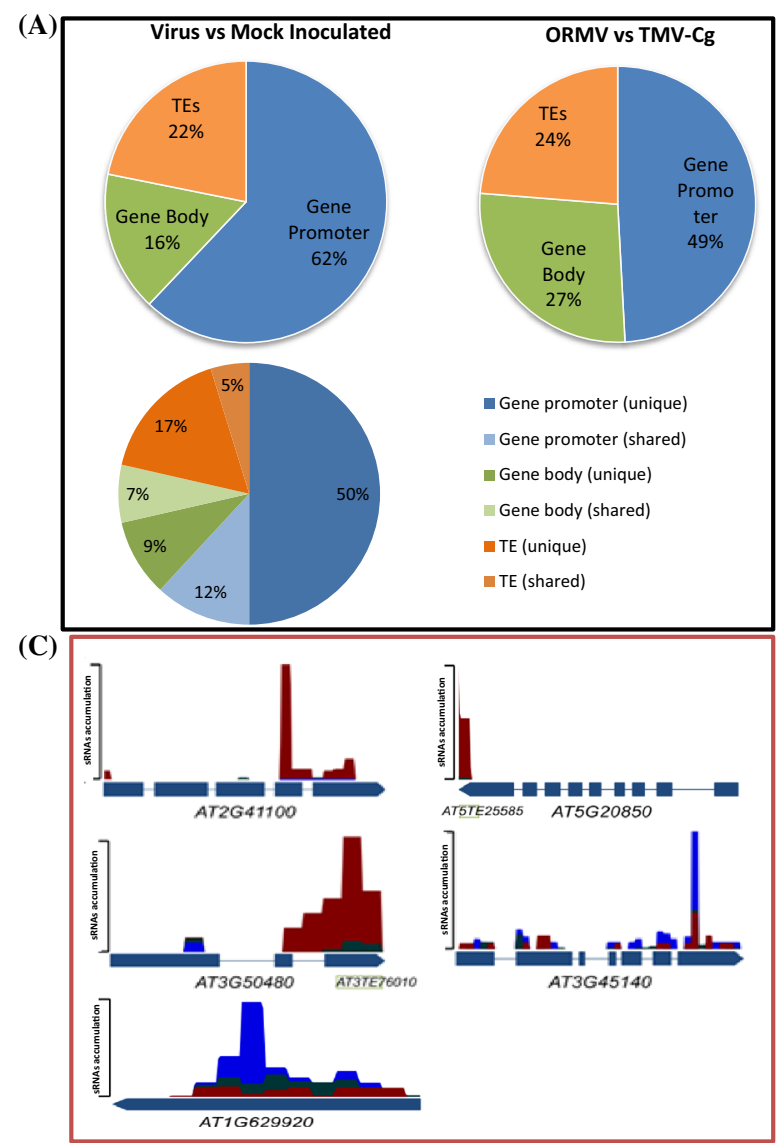

Fig. 1 Schematic representation of differential distribution of 24-nt sRNAs in selected genes or different regions in Arabidopsis thaliana plants infected with Tobamoviruses (ORMV or TMV-Cg). a Pie graph showing the percentage of differentially represented regions mapped with the analyzed sRNAs: gene promoter, gene body or transposon near genes. Left upper panel: comparison between infected vs mock-inoculated plants. Right upper panel: compari-

On the other hand, genes with 24-nt sRNAs mapped to the gene body region exhibited higher relative levels of mRNA and only one of these genes showed no differences of expression with any of the evaluated Tobamoviruses (Fig. 2b). This case can be explained by the antagonism between the SA and JA pathways. Lox2 is a JA-biosynthesis gene sensitive to suppression by SA accumulation (Leon-Reyes et al. 2010). Interestingly, the expression levels of this group of genes showed a positive correlation with sRNAs abundance in infected versus non-inoculated plants (Table 1a; Fig. 2b). Finally, we observed that genes nearby to transposon with DA sRNAs also showed higher relative levels of mRNA in infected plants (Table 1a; Fig. 2c).

These results suggest that viral infection modifies the transcription of different genes and that could be as consequence of changes in the profiles of 24-nt sRNAs that mapped to different gene regions or to TEs nearby genes.

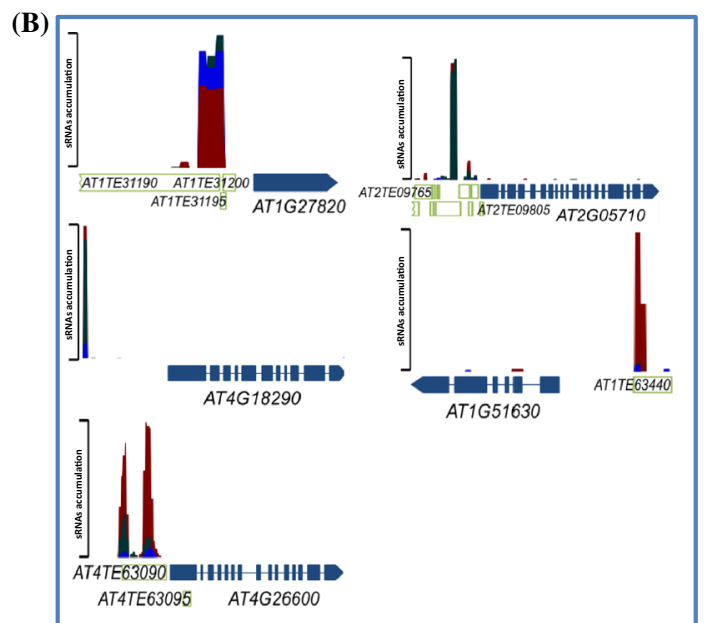

(D)

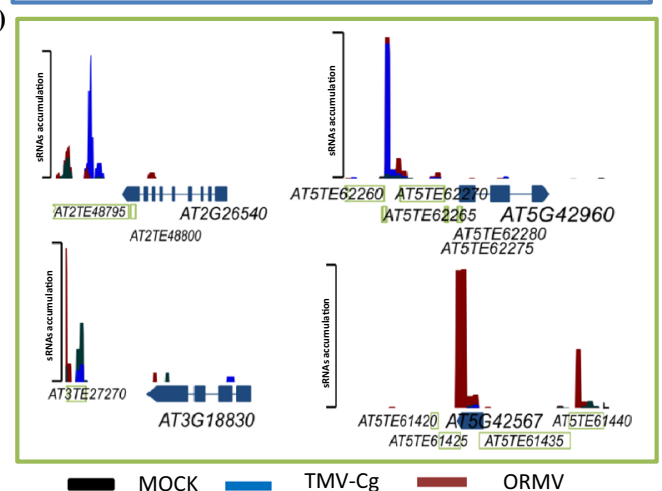

son between both strains of viruses. Left bottom panel: comparison between infected vs mock-inoculated plants in unique or shared genes. Distribution of 24-nt sRNA mapped to b gene promoter of the selected genes (blue square), c gene body (red square) or d transposons within or nearby genes (green square). The $y$-axis represents the abundance of sRNAs and the $\mathrm{x}$-axis represents promoter, gene body or transposon regions

\section{RNA-directed DNA methylation and demethylation mechanism have a role in the transcriptional changes induced by the infection}

To assess if the changes in mRNA levels of the selected genes depend on alterations of methylation levels linked to RdDM pathway, we evaluated the expression of these genes in different mutant plants. For this purpose, we used plants with alterations in various components of the RdDM pathway and a triple methyltranferase mutant (demethylases). The evaluated mutants were the RNA dependent RNA polymerase 2 mutants, unable to synthesize double stranded RNA: $r d r 2.5$; the argonaute 4 mutant, unable to guide methylation processes: ago4.1; the mutant without a common subunit of polymerases PolIV and PolV: $n r p d 2 a$ and a triple demethylase mutant: ros1-dml2-dml3, denominated $r d d$ (Le et al. 2014). Most of the selected genes presented an unaltered expression profile after the infection in the three 
(A)

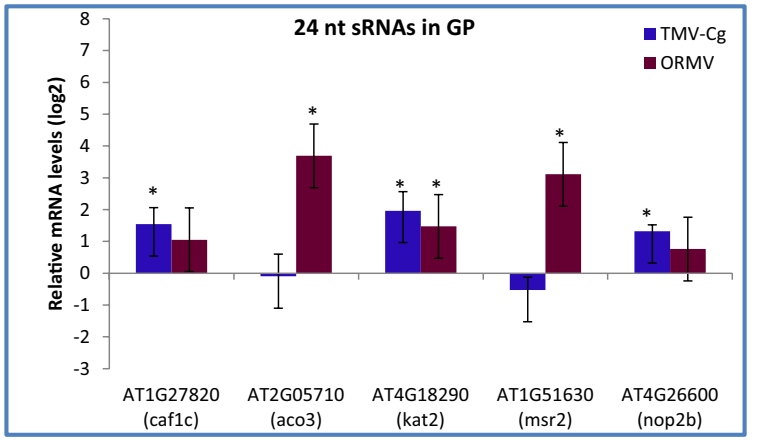

(C)

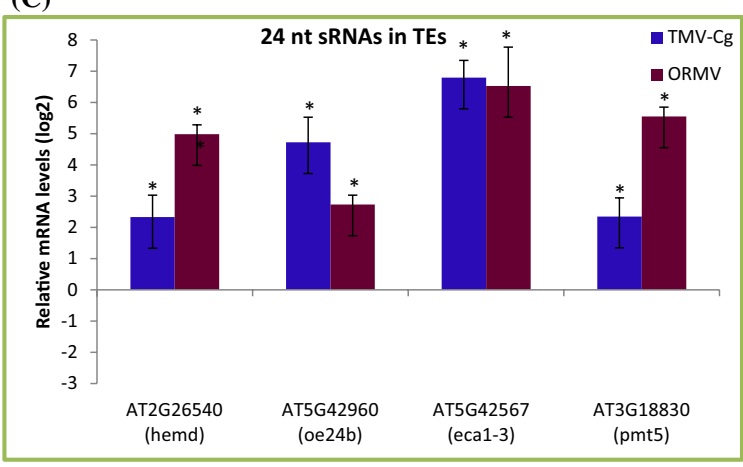

(B)

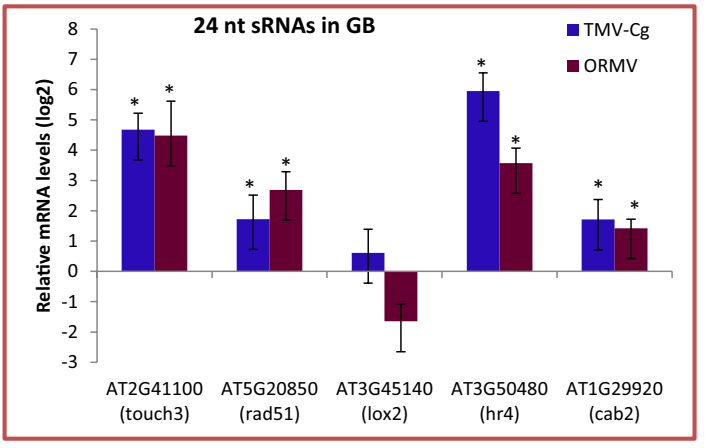

Fig. 2 Molecular analysis of target genes in wild type plants (Col-0). qRT-PCR analysis of mRNAs of selected genes at 4dpi of TMV-Cg and ORMV-infected plants (in relation to mock-inoculated plants) with differential accumulation of 24-nt sRNA in a gene promoter

evaluated RdDM mutants of the RdDM machinery (Fig. 3a, b, c), at 4 dpi. The same was observed for the $r d d$ mutant (Fig. 3d). mRNA levels of the selected genes lost the regulatory impact produced by viral infection as an outcome of the disruption of the RdDM machinery or as a consequence of decreased demethylation. Thus, the alteration of mRNA levels of the selected genes during viral infection could be regulated by changes in DNA methylation patterns, which in turn are directed by sRNAs.

\section{Phenotypic evaluation of RdDM and rdd Arabidopsis mutants infected with two strains of Tobamoviruses}

Next, we analyzed the symptoms produced during ORMV and TMV-Cg infection in $r d r 2.5$, ago4.1, nrpd2a and $r d d A$. thaliana plants. In Col-0 ecotype, the two Tobamoviruses exhibited differences in symptom severity and ORMV produced the most severe phenotype (Zavallo et al. 2015).

Initially, we performed a visual characterization (Fig. 4). Typical symptoms caused by viral infection are reduced rosette growth, delayed flowering, leaf chlorosis and senescense induction. Col-0 plants inoculated with TMV-Cg showed a smaller rossette size and greater chlorosis than controls. This effect was more pronounced in ORMV
(GP) (blue square), b in gene body (GB) (red square) or in transposons (TEs) (green square). $\log _{2}$-fold change of selected genes is shown. Error bars represent SE. $* \mathrm{p} \leq 0.05$. The blue and red bars refer to plants infected with TMV-Cg or ORMV, respectively

inoculated plants. Interestingly, $r d r 2.5$ and ago4.1 mutants were less affected by the viral infection. These mutants showed minor leaf chlorosis and decreased rosette growth inhibition, at 16 dpi. Furthermore, the severity of the symptoms between the two viruses was similar and less evident than in wild type plants. Particularly, the nrpd2a mutant showed no leaf chlorosis, whereas the triple mutant $r d d$ did display this symptom, although with limited growth inhibition (Fig. 4a). Another typical symptom of viral infection is the delayed emergence of bolting. Col-0 ecotype plants inoculated with ORMV showed shorter bolting than TMVCg-inoculated plants; similarly, the ago4.1 mutants presented a comparable disease phenotype than wild type plants (Fig. 4b). In addition, the $r d r 2.5$ and $r d d$ mutants showed no delay in bolt emergence when infected with TMV-Cg, Surprisingly, the double nrpd2a mutants showed null variation with either of the viruses (Fig. 4b). In parallel, we performed RT-qPCR assays using specific primers for replicase to assess gene virus accumulation at $7 \mathrm{dpi}$. Similar amounts of viral RNA was evident in Col-0 and all evaluated mutants (Fig. 5). Thus, the alteration of symptoms cannot be explained by a differential viral accumulation. To obtain a more thoroughly phenotypic characterization of physiological impacts of the infection, we measured and quantitated 
(A)

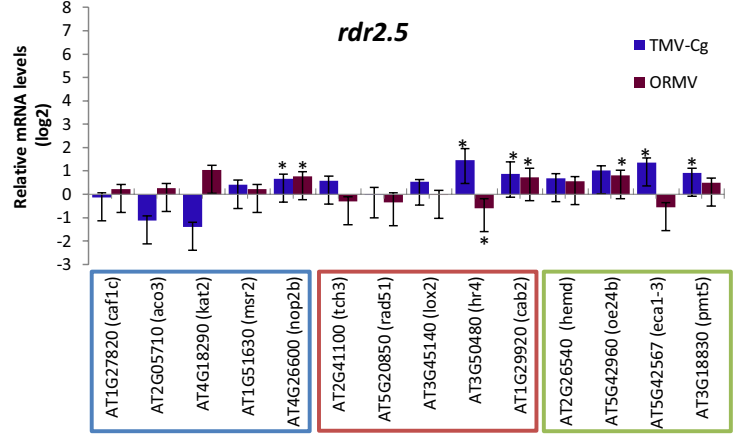

\section{(C)}

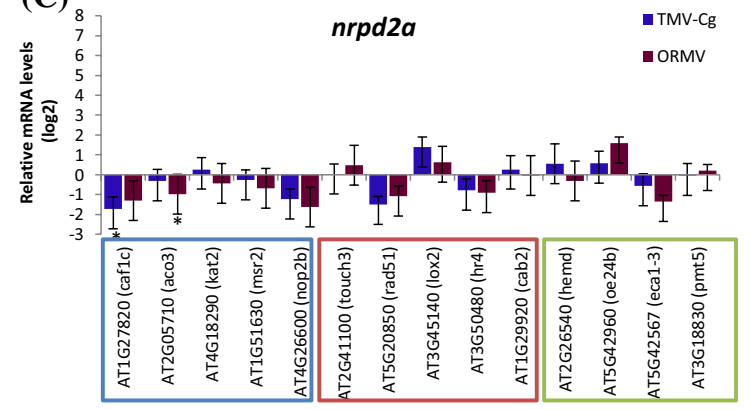

Fig. 3 Molecular analysis of target genes of RNA-directed DNA Methylation (RdDM) machinery and triple demethylase mutants. RT-qPCR analysis of selected genes at 4dpi of TMV-Cg and ORMV infected plants in comparison to mock-inoculated plants. $\log _{2}$-fold change of selected genes at 4dpi are shown in a RNA-dependent RNA polymerase 2 (rdr2.5) mutant; b argonaute 4 (ago4.1) mutant;

several important traits: bolt height (Fig. 6a), rosette fresh weight (Fig. 6b), chlorophyll accumulation (Fig. 6c), anthocyanin accumulation (Fig. 6d), phenolic accumulation (Fig. 6e) and carotenoid accumulation (Fig. 6f). Relative loss of fresh weight is a marker of senescence that is a common physiological process induced by viral infection. As expected, Col-0, $r d r 2.5$ and ago4.1 plants inoculated with both Tobamoviruses presented significant differences regarding fresh weight, although growth inhibition was lower in both mutants. Interestingly, the $n r p d 2 a$ mutant and the triple mutant $r d d$ showed no significant differences in rosette weight in comparison to mock-inoculated plants (Fig. 6g).

Decrease of chlorophyll level in leaves during senescence process is another well-characterized pattern occurring under biotic or abiotic stresses (Pružinská et al. 2005; 2012). To confirm the findings of the visual characterization, we also measured chlorophyll levels of the different mutants infected with the two viruses. No significant differences were detected in wild type plants inoculated with TMV-Cg. In contrast, ORMV infection considerably reduced the amount of chlorophyll at $16 \mathrm{dpi}$. Notably, none of the RdDM pathway mutants showed clear symptoms of senescence except for the methyltransferase mutants, which were affected only by ORMV (Fig. 6c, g).
(B)
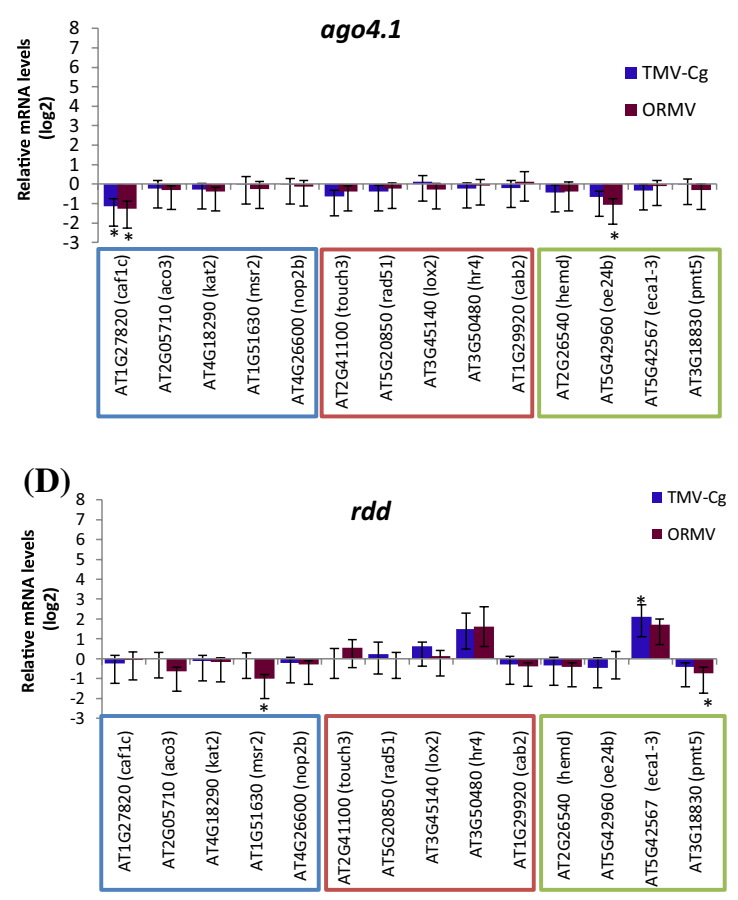

c nrpd2a (subunit of polymerase IV and V) mutant and $\mathbf{d}$ triple demethylase (rdd: ros; dml2; dml3) mutant. The blue, red and green boxes display the genes mapped by sRNAs in gene promoter, body regions or in transposons, respectively. Error bars represent SE. ${ }^{*} \mathrm{p} \leq 0.05$. The blue and red bars show plants infected with TMV-Cg or ORMV, respectively

Anthocyanins are polyphenolic compounds induced during the senescence under stress and participates in many processes, including the defense against different pathogens (Landi et al. 2015; Liu et al. 2018). Phenolic compounds are secondary metabolites produced by the plant against different pathogens and, like anthocyanins, are produced under different stresses (Mazid et al. 2011). Wild type and ago4.1 mutant plants infected with both Tobamovirus displayed increased levels of anthocyanins and total phenolic compounds. Nevertheless, no evident differential accumulation of these compounds was detectable in the other mutants used in this assay (Fig. 6d,e). On the other hand, carotenoids are antioxidant molecules induced by oxidative stress and their accumulation is reduced during viral infection (Havaux 2014; Ibdah et al. 2014). Col-0, $r d r 2.5$ and $r d d$ plants showed significant differences of this compound only with ORMV infection. However, the ago4.1 mutants showed the lowest accumulation of this compound upon infection of any viruses. Notably, the polymerase IV/V impaired mutant showed increased levels of carotenoids with the two viruses (Fig. 6f).

Altogether, the production of symptoms during viral infection is partly caused as a result of the action of RdDM pathway guided by sRNAs. Probably, this is due to changes 


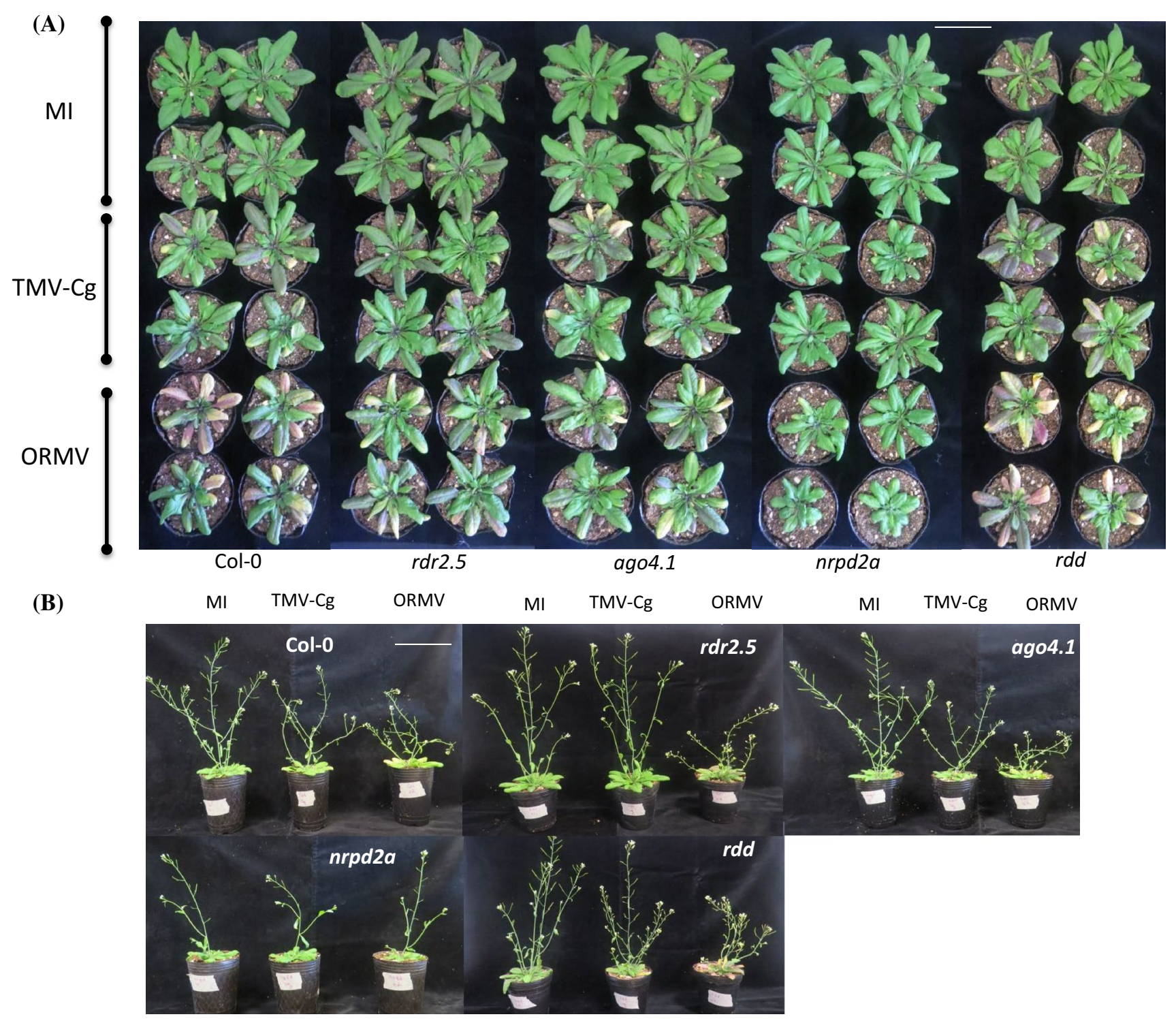

Fig. 4 Visual phenotypic characterization. a Photography of Arabidopsis thaliana Col-0 (wild type), RdDM and $r d d$ mutants infected with ORMV or TMV-Cg viruses. At 16 days post-inoculation (dpi), the bolts were cut-off the plants before photographing to obtain better images. b Photography of bolt at 16dpi form plants inoculated with

that modify the dynamic balance between methylation and demethylation events.

\section{Discussion}

Although the mechanisms by which a viral infection induces symptoms have been widely studied (Bilgin et al. 2003; Dardick 2007; Inaba et al. 2011; Jay et al. 2011; Shimura et al. 2011; Smith et al. 2011; Yang et al. 2019), the role of epigenetics in the production of symptoms is still unclear. DNA methylation is the major epigenetic hallmark both evaluated viruses. $r d r 2.5$ : RNA-dependent RNA polymerase 2 mutants; ago4.1: argonaute 4 mutants; nrpd2a: subunit of polymerase IV and V mutants; $r d d$ : triple demethylase (ros; dml2; dml3) mutant. Bar, $1 \mathrm{~cm}$

associated to TEs or repetitive elements regulation by means of transcriptional gene silencing, which is mainly directed by 24-nt sRNAs. Here, we tested the effect of 24-nt sRNAs after a viral infection, emphasizing the role of the RdDM pathway in the regulation of symptom induction.

Initially, we observed that viral infection altered the profile of 24-nt sRNAs at early times of infection. We focus in this particular type of siRNAs since their main role in transcriptional gene silencing. In accordance with similar evidence published in the last years (Zavallo et al. 2015; Guo et al. 2017), in this work the viral inoculation modified the balance of 24-nt sRNAs profiles that 


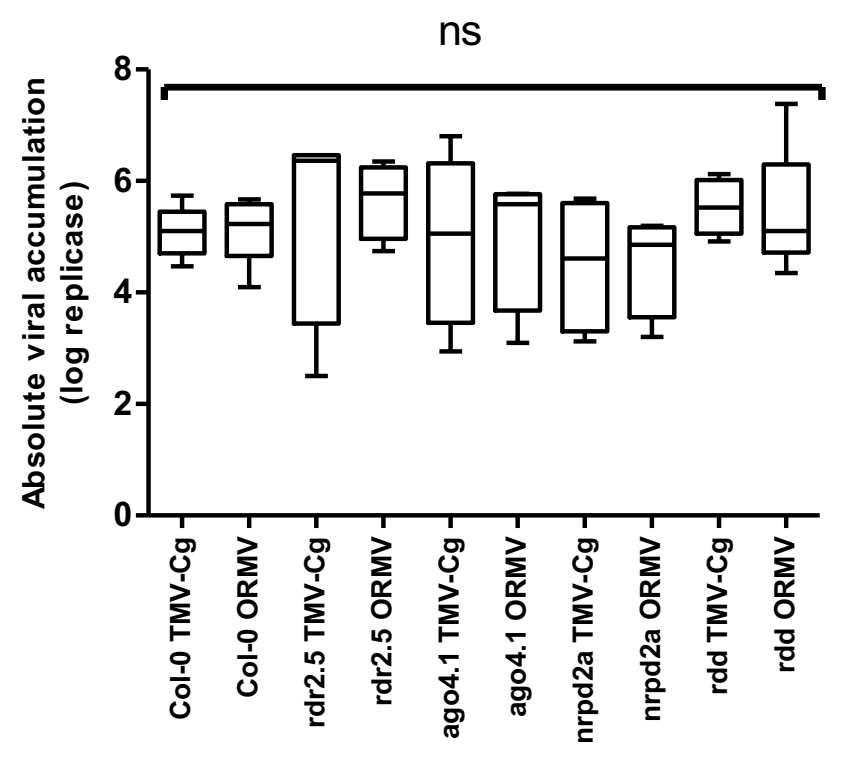

Fig. 5 Viral accumulation level. Absolute viral loads for Col-0 and Arabidopsis thaliana $\mathrm{RdDM} / r d d$ mutants inoculated at 7 dpi obtained using Tobamovirus replicase specific qPCR primers. ns: no significant differences mapped to coding regions or to transposons located near genes. One possible explanation for this alteration is that, by means of endogenous machinery, the plant defense generates vsRNAs and therefore controls the infection. Concomitantly to, this process defense could affect the levels of other sRNAs. In addition, viral counter-defense actions, like the activation/expression/induction of silencing suppressors proteins, could be interacting with components of the RdDM pathway, thus affecting their function. For example, Cucumber mosaic virus suppressor $2 \mathrm{~b}$ interacts with AGO4 protein and reduces its activity (Hamera et al. 2012). Moreover, the RNA decay mechanism and sRNA function have a clear association and, consequently, a switch of RNA decay impacts in the accumulation of many endogenous genes regulated by silencing (Martínez de Alba et al. 2015). Furthermore, Conti et al., (2017b) demonstrated that viral infection alters RNA decay machinery, which in turn leads to impact on the silencing pathways. Therefore, changing sRNA-mediated functionality could be another way to explain the viral influence on the profile of 24-nt accumulation (Conti et al. 2017b).
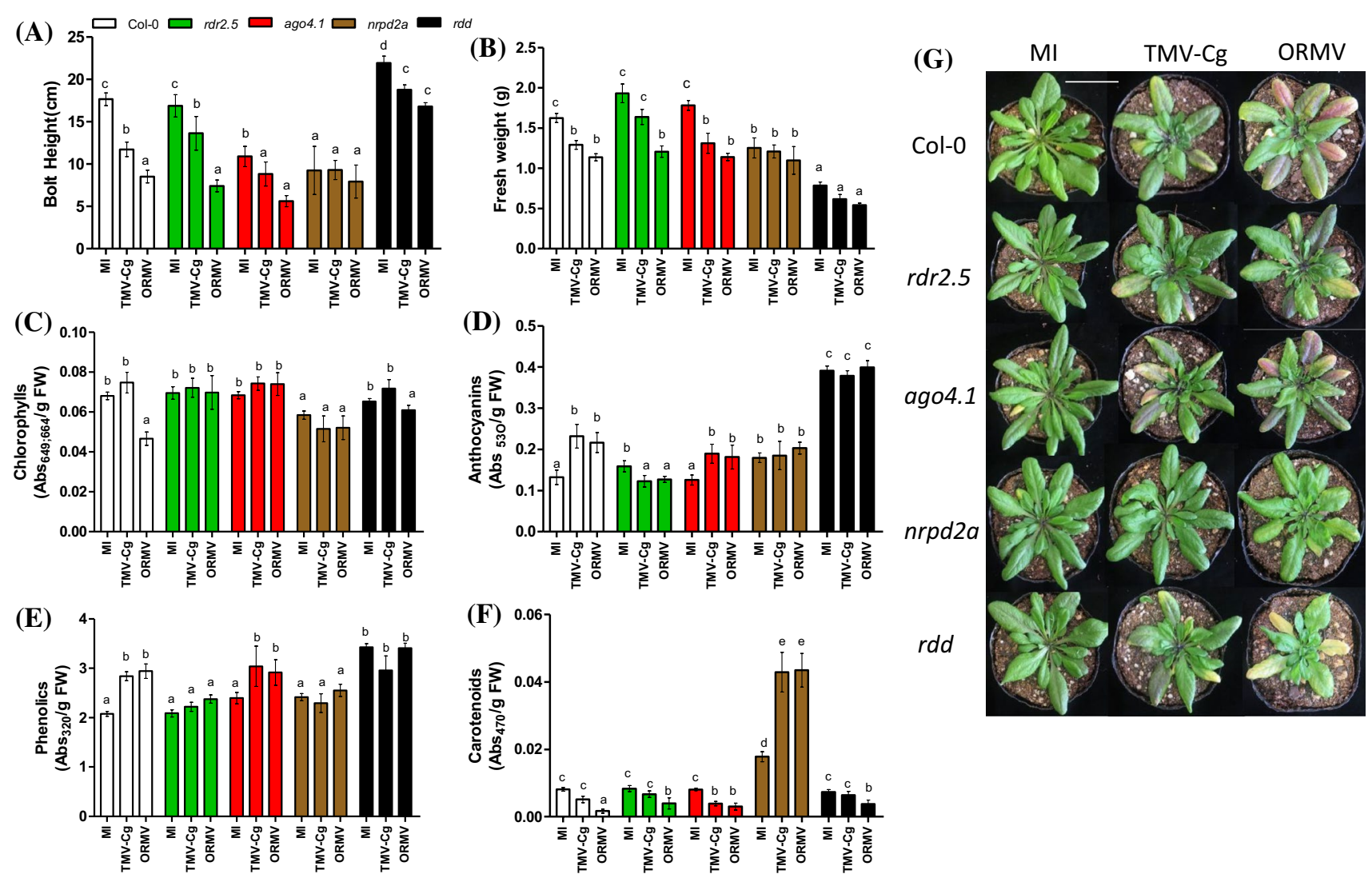

Fig. 6 Phenotypic measurements in wild type, RdDM and $r d d$ mutants infected with two Tobamoviruses. Arabidopsis thaliana leaves of the different genotypes were harvested 16 dpi. a Bolt height; b Rosette Fresh weight; c chlorophyll accumulation; d anthocyanin accumulations; e Phenolic accumulation; f carotenoid accumula- tion. The different letters indicate significant differences between MI/ TMV-Cg and ORMV inoculated samples. Error bars represent standard error. $\mathrm{p} \leq 0.05$. g Photograph of Col- 0 , RdDM and $r d d$ mutants inoculated with both viruses at $16 \mathrm{dpi}$ (the bolt was cut before photographing to obtain better images). Bar, $1 \mathrm{~cm}$ 
The analysis of the infected plants, in comparison to non-infected plants, demonstrated that most of the DA sRNAs clusters mapped in promoter regions that sometimes contain a TE. To a lesser extent, sRNAs mapped to transposons located near genes and, finally, a smaller percentage mapped within gene body regions. We also observed that the abundance of the 24-nt sRNAs that mapped to promoter regions was lower in infected plants in comparison to non-infected plants and transcription level of the genes mapped by these sRNAs was higher in Col-0 ecotype (when we compare infected versus mock inoculated plants). This finding is consistent with the knowledge that DNA methylation in regulatory regions inhibits transcription; therefore, a negative correlation between the amount of sRNAs (associated to a reduced level of methylation) and the level of mRNA is expected (Mette et al. 2000; Přibylová et al. 2019). On the other hand, controversy surrounds the effect of methylation of gene body regions. Whereas some researchers reported that the methylation of these regions promotes the expression of certain genes, others demonstrated otherwise (Li et al. 2012; Yang et al. 2015). Herein, genes with increased abundance of sRNAs in gene body regions showed also higher relative levels of mRNAs in infected plants. These patterns could be explained by a mechanism, proposed by Harris et al. (2018), in which the methylation reader SUVH1/3 DNAJ complex enhances transcription.

Furthermore, we identified a common positive correlation between the amount of 24-nt sRNAs and the expression of genes located near TEs. Of the four TEs located near genes evaluated in this study, three belong to Helitron family and the other to the DNA/MuDR family. Notably, almost every evaluated gene (13/14) has TEs near non-coding regions (5-UTR and 3-UTR). Most of the detected TEs correspond to Helitron family. Indeed, researchers have identified both types of TEs associated with genetic and epigenetic variation located in proximity to disease resistance NBS-LRR genes (Kawakatsu et al. 2016; Underwood et al. 2017; Cambiagno et al. 2018). A clear example of this regulation was demonstrated, when an helitron transposon element in the ROS 1 gene promoter negatively controls ROS 1 expression, whereas DNA methylation of an RdDM target sequence between ROS1 5' UTR and the promoter TE region antagonizes this helitron TE in regulating ROS1 expression. The authors showed that the ROS1 promoter functions like a thermostat to sense DNA methylation levels and regulates DNA methylation by controlling ROS1 expression (Lei et al. 2015).

Altogether, we confirm that Tobamovirus viral infection altered the profile of 24-nt sRNAs and, in turn, these small molecules can regulate gene expression.

Second, we propose that (de) methylation is an important controller of gene transcription. Indeed, the different RdDM knockout mutants as well as the triple DNA demethylase mutant $r d d$ were insensitive to induction of gene expression after viral infection. The suppression of genes required by the methylation machinery guided by 24-nt sRNAs in order to promote TGS inhibited the increase of mRNA levels. By contrast, the wild type plants did present upregulated levels of mRNAs upon Tobamovirus infection. First, we attributed the differences of gene expression to a lower susceptibility of the mutants to the virus. However, this hypothesis was discarded because the (de) methylation mutants and wild type plants accumulated similar levels of viruses. Thus, this deregulation may be due to modifications in the RdDM pathway. Therefore, the genes may be directly affected by RdDM machinery or may be indirectly altered by the action of other targets that modify closed and open chromatin states regulated by TGS (Harris et al. 2018). Another possible explanation could be that in RdDM pathway mutants, $\mathrm{CHH} / \mathrm{CHG}$ methylation levels may be low or null compared to the wild type plant and therefore the viral infection does not produce any change in the methylation levels of the evaluated genes. On the contrary, the triple mutant $r d d$ shows hypermethylated regions and again no changes could be generated after the viral infection (Karolchik et al. 2003; Stroud et al. 2013).

Interesting, Zhong et al. (2013) demonstrated that the presence of a TE is an important factor for Pol V stably assembles to a given genomic locus. Therefore, Pol V may be associated with regions where promoters and transposons overlap near Pol V targets. In addition, the findings in their study indicate that genes close to methylated transposons are often associated with reduced genetic expression (Zhong et al. 2013). In this context, Gagliardi et al. (2019) showed that a MITE likeTE with inverted repeats (IR), located near the WRKY6 locus, dynamically regulates the expression of these genes by altering the chromatin topology. They evidenced a non-canonical mechanism of regulation in which the enrichment of DNA methylation in flanking regions of WRKY6 is associated with the formation of chromatin loops that ends up altering transcription rates. Although a reduction of methylation in these regions together with stable methylation in one intron correlates with the formation of an intragenic loop that inhibits the transcription of the gene (Gagliardi et al. 2019). Interestingly, most of the genes evaluated in this study had TEs near 5-UTR/3-UTR and 24-nt sRNAs that mapped to promoter or coding regions. Possibly, the RdDM pathway directs changes in methylation patterns and these changes produce modifications in DNA topology. Therefore, these variations of topology would open or close regulatory regions, thus promoting or inhibiting the entry of RNA polymerase II and therefore modifying the transcription of these genes. For example, At3g50480 locus, which encodes a homologue of RPW8, a canonical disease-resistance protein that confers resistance to powdery mildew (Xiao et al. 1997) showed hypo- and hypermethylation of $\mathrm{mCs}$ in every sequence context indicating that 
active remethylation or demethylation of cytosines can occur dynamically in response to bacterial pathogen (Dowen et al. 2012). A hypothesis could be that the disruption in DNA methylation/demethylation equilibrium induced by biotic stress could cause a change in the expression patterns of certain genes, but further study is required.

Third, we provide evidence which suggest that (de) methylation could impact on the production of symptoms induced by viral infection. All tested mutants showed differences in at least one of the phenotypic variables measured in comparison with Tobamovirus-inoculated Col-0 ecotype, at later stages of infection. Although $r d r 2$ and ago4 are the mutants that most closely resemble Col- 0 plants, both had reduced leaf chlorosis. In addition, the $r d r 2$ mutants also accumulated lower amounts of anthocyanin and phenolic compounds. Plants with mutation in the common NRPD subunit of polymerases IV and V, which are involved in RdDM machinery, showed fewer symptoms (no bolt growth inhibition, no chlorosis and no decrease in fresh weight or in accumulation of anthocyanin and phenolic compounds) in comparison to wild type plants, but strikingly showed very high levels of carotenoids. Carotenoid levels decrease after viral infection; therefore, the regulatory mechanism in $n r p d$ mutant could be deregulated as a consequence of decreased methylation. It is important to note that there are other mechanisms involved in the induction of these compounds. Although regulation is more complex, methylation may have a role in this process. The triple demethylase mutants showed an intermediate phenotype with viral infection: lower fresh weight inhibition and, like Col-0 plants, lower levels of chlorophyll and carotenoids were observed.

If we analyze the RdDM pathway in detail, we can hypothesize that $r d r 2$ and ago 4 mutants produce less impact in the symptoms production than nrpd plants upon viral infection because of the existence of other proteins with functional redundancies or because of the action of the noncanonical pathway of methylation. Indeed, some sRNAs of the PTGS via RDR6 and probably AGO6 could be used as guides to activate RdDM (Cuerda-Gil and Slotkin 2016). Both polymerases IV and V are major components of the RdDM machinery. Pol IV transcribes sRNAs from target loci and physically interacts with RDR2, whereas Pol V recruits AGO4 and directs the methylation of complementary sequences (López et al. 2011; Haag et al. 2012). The nrpd mutation affects an essential subunit shared by both Pol IV and Pol V and this disruption may explain the almost complete absence of symptoms. Therefore, the mutation may not only lead to the inhibition of methylation, but also to the absence of chromatin remodeling factors that interact with Pol V and regulate the transcriptome.

Furthermore, changes in symptomatology could be due to a global effect of the disruption of the methylation machinery that impairs endogenous TGS regulation. For example,
Aconitase (aco) coding gene produces an enzyme that can catalyze the conversion of citrate to isocitrate through a cis-aconitate intermediate. Arabidopsis thaliana knockout plants for the aco gene have lower chlorosis and are more tolerant to oxidative stress (Moeder et al. 2007). Moeder et al., in the same research, demonstrated that Nicotiana plants silenced by VIGS (90\% reduction in enzyme activity) have reduced pathogenic inductive cell death (Moeder et al. 2007). In the present study, all the evaluated mutants displayed lower levels of chlorosis and loss the upregulation of aco3 mRNA levels induced by the infection; which suggests that (de) methylation could regulate this process. The absence of chlorosis in the nrpd mutant could be explained by the interruption of two essential components (PoI IV and Pol V) of the RdDM pathway. This is a clear difference with other mutants, ago4 and $r d r 2$, with redundancy in protein families (Havecker et al. 2010; Willmann et al. 2011).

On the other hand, changes in TE methylation located near genes could be affecting DNA topology. A recent study reported that senescence induced by darkness activates young TEs of the DNA and Helitron families (Minerva S. TrejoArellano et al. 2019). This physiological process is associated with negative histone regulation and replication remodelers that could mobilize these TEs. Minerva S. Trejo-Arellano et al. (2019) also demonstrated that changes in the regulation of the RdDM pathway alter the senescence process.

Altogether, we propose that chlorosis, a characteristic symptom of viral infection, possible as well as other symptoms, may be regulated by alterations in methylation patterns that affect both TGS and the three-dimensional structure of DNA and all these DNA modifications consequently may affect the levels of transcription.

In conclusion, this work represents the initial step in exposing that DNA methylation directed by endogenous sRNAs has a central role in the production of differential symptoms in plants. Probably is caused by changes that modify the dynamic balance between methylation and demethylation events.

\section{Experimental procedures}

\section{Plant material}

Seeds of Arabidopsis thaliana were stratified at $4{ }^{\circ} \mathrm{C}$ for 3 days. All plants were grown under standard conditions in controlled environmental chambers, at $22{ }^{\circ} \mathrm{C}$ and a $16 \mathrm{~h}$ white light: $8 \mathrm{~h}$ darkness photoperiod (Boyes et al. 2001). The rdr2.5, ago4.1, nrpd2a and rdd lines were all in the Col-0 background (Ariel et al., 2014). 


\section{Viral infection and sample collection}

Arabidopsis plants were mechanically inoculated with carborundum into their third true leaf at stage 1.08 (Boyes et al. 2001). The quantitation of TMV-Cg and ORMV inoculation were performed by infecting Nicotiana tabacum (NN) plants with serial dilutions of viral extracts. Local lesions (LL) were counted and the inoculum stored at $-80{ }^{\circ} \mathrm{C}$ until infection. Subsequently, $5 \mu \mathrm{l}$ of ORMV and TMV-Cg inoculum diluted (100 LL per plant) in $20 \mathrm{mM}$ phosphate buffer $(\mathrm{pH}$ 7) was added to the leaf and its surface was gently abraded. The mock-inoculated plants were buffer rubbed instead. The systemic leaves 8 and 11 were sampled 4 days post inoculation (dpi) to isolate RNA and 7 dpi to quantify viral accumulation. Six independent plants were used for each treatment. Pigment measurement was performed in individual leaves 16 dpi.

\section{Bioinformatics analysis}

Original data used in Zavallo et al.'s study were reanalyzed (Zavallo et al. 2015). FASTX-Toolkit (version 0.0.13) was used to perform adaptor and quality trimming on sRNA-seq experiment reads for each library. Bash command was used to filter and select 24nt-length reads, whereas ShortStack software (versión 3.8.5) (Johnson et al. 2016) was used to map and quantitate sRNA reads to the reference Arabidopsis genome TAIR 10 assembly. In more detail, cleaned 24nt-lenght reads were mapped to reference genome without the -locifile option. Then, bam files of each treatment were merged with samtools merge into a single bam sRNA mapping file. This file was used to re-run ShortStack using the -bamfile option with different feature annotation files with the-locifile option such as genes, promoters and TEs. Count files of each run were subjected to further analysis to detect differential accumulation (DA) sRNAs between treatments with edgeR package using the glm model. Three sets of DA sRNAs were analyzed: DA sRNAs within genes, DA sRNAs within promoters (minus $2.5 \mathrm{~KB}$ from gene transcription start site) and DA sRNAs within TEs (located up to $2 \mathrm{~kb}$ of the 5-UTR and 3-UTR regions of the selected genes). Software deepTools (version 3.3.1) was used to perform sRNA distribution plots of selected features.

\section{RNA isolation and Real time quantitative polymerase chain reaction (qPCR)}

Total RNA was isolated from frozen Arabidopsis thaliana leaf tissues using TransZol Reagent (TransGen Biotech, Beijing, China) and treated with DNAse I (Invitrogen, California,USA). Subsequently, cDNA was synthesized using MMLV (Invitrogen, California, USA) and random primers according to the manufacturer's instructions
(Invitrogen). All qPCR experiments were carried out in an ABI StepOne Plus Real Time PCR System (Applied Biosystems, California, USA). Table SI1 displays the oligonucleotide primer sets used for qPCR. Arabidopsis EF1alpha gene was used as reference for normalization in each experiment. For each gene measurement, six biological replicates were used for each gene measurement in each treatment. qPCR data analysis and primer efficiencies were obtained using LinReg PCR software (Ruijter et al. 2009). Relative expression ratios and statistical analysis were performed using fgStatistics software interface, which uses the $2-\Delta \Delta \mathrm{Ct}$ method to analyze the relative changes in gene expression (Livak and Schmittgen 2001). A p value below 0.05 was set as the cut-off for statistical significance.

\section{Physiological and pigment measurements}

First, bolt height of the different treated plants was measured with a ruler, whereas fresh weight was determined with an analytical balance. Pigments were extracted from individual samples of leaf 5 at 16 dpi. Chlorophylls and carotenoids were extracted using $96 \%$ ethanol. The measurement of anthocyanins and soluble phenolic compounds was performed by placing the already weighed leaves in acidified methanol (99: 1, v/v) at $4{ }^{\circ} \mathrm{C}$ for $48 \mathrm{~h}$ (Rabino and Mancinelli 1986; Leone et al. 2014). Absorbance of $0.2 \mathrm{ml}$ was measured at 664, 649, and $470 \mathrm{~nm}$ (chlorophylls and carotenoids), 530 and $657 \mathrm{~nm}$ (anthocyanins) or $320 \mathrm{~nm}$ (phenolic compounds) in a Multiskan Spectrum (Thermo Fisher Corp., Waltham, MA, U.S.A.). Chlorophyll concentrations were calculated using the following equations: $\mathrm{Ca}+\mathrm{b}=$ total chlorophylls $(\mu \mathrm{g} / \mathrm{ml})=1$ $496 / 22.24 \times \mathrm{A} 649+5.24 \times \mathrm{A} 664, \mathrm{Ca}=$ chlorophyll a $(\mu \mathrm{g} /$ $\mathrm{ml})=13.36 \times \mathrm{A} 664-5.19 \times \mathrm{A} 649$, and $\mathrm{Cb}=$ chlorophyll $\mathrm{b}(\mu \mathrm{g} / \mathrm{ml})=27.43 \times \mathrm{A} 649-8.12 \times$ A664. Carotenoid concentrations were assessed using $\mathrm{Cc}=$ total carotenoids $(\mu \mathrm{g} /$ $\mathrm{ml})=(1000 \times \mathrm{A} 470-2.13 \times \mathrm{Ca}-97.64 \times \mathrm{Ca}) / 209$. Anthocyanin contents were evaluated using A530 - 0.25 × A657. The experiment was repeated three times independently.

\section{Statistical analyses}

Statistical analyses were performed with one-way ANOVA test using INFOSTAT software (InfoStat/Professional version 2008, Grupo InfoStat. FCA, Universidad Nacional de Córdoba, Córdoba, Argentina, https://www.infostat. com.ar/). The significance level for all tests was $\alpha=0.05$. Appropriate transformations of the primary data were used when needed to meet the assumptions of the analysis. The phenotypic characterization was assessed by analyzing the data by factorial ANOVA, with viral treatment and genotype as factors. 
Acknowledgements We thank Federico Ariel, Pablo Manavella and Martin Crespi for the $r d r 2, n r p d 2 a$, ago4 and $r d d$ lines, respectively.

Author contributions ML: Investigation, Methodology, Visualization, Writing original draft and Writing review and editing. DZ: Investigation, Bioinformatics analysis, Data curation, Writing review and editing. AV: Investigation, Methodology, Writing review and editing. SA: Conceptualization, Funding acquisition, Investigation, Project administration, Resources, Supervision, Writing review \& editing.

Funding This research was supported by grants from CONICET (Consejo Nacional de Investigaciones Científicas y Técnicas) and ANPCyT (Agencia Nacional de Promoción Científica y Tecnológica) PICT 20141163 and PICT 2015-1532.

\section{Compliance with ethical standards}

Conflicts of interest The authors declares that there are no conflicts of interest.

\section{References}

Aguilar I, Sanchez F, Martin AM, Martinez-Herrera D, Ponz F (1996) Nucleotide sequence of Chinese rape mosaic virus (oilseed rape mosaic virus), a crucifer tobamovirus infectious on Arabidopsis thaliana. Plant Mol Biol 30:191-197. https://doi. org/10.1007/BF00017814

Akimoto K, Katakami H, Kim HJ, Ogawa E, Sano CM, Wada Y, Sano H (2007) Epigenetic inheritance in rice plants. Ann Bot 100:205-217. https://doi.org/10.1093/aob/mcm110

Axtell MJ (2013) ShortStack: comprehensive annotation and quantification of small RNA genes. RNA 19:740-751. https://doi. org/10.1261/rna.035279.112

Baulcombe D (2004) RNA silencing in plants. Nature 431:356-363. https://doi.org/10.1080/09720073.2014.11891518

Bazzini AA, Manacorda CA, Tohge T, Conti G, Rodriguez MC, Nunes-Nesi A, Villanueva S, Fernie AR, Carrari F, Asurmendi S (2011) Metabolic and miRNa profiling of TMV infected plants reveals biphasic temporal changes. PLoS ONE. https:// doi.org/10.1371/journal.pone.0028466

Bewick AJ, Schmitz RJ (2017) Gene body DNA methylation in plants. Curr Opin Plant Biol 36:103-110. https://doi. org/10.1111/mec.13536.Application

Bhattacharyya D, Chakraborty S (2018) Chloroplast: the Trojan horse in plant-virus interaction. Mol Plant Pathol 19:504-518. https://doi.org/10.1111/mpp.12533

Bilgin DD, Liu Y, Schiff M, Dinesh-Kumar SP (2003) P58 IPK, a plant ortholog of double-stranded RNA-dependent protein kinase PKR inhibitor, functions in firal pathogenesis. Dev Cell 4:651-661. https://doi.org/10.1016/S1534-5807(03)00125-4

Bilgin DD, Zavala JA, Zhu J, Clough SJ, Ort DR, Delucia EH (2010) Biotic stress globally downregulates photosynthesis genes. Plant, Cell Environ 33:1597-1613. https://doi.org/10.1 111/j.1365-3040.2010.02167.x

Borges F, Martienssen RA (2015) The expanding world of small RNAs in plants. Nat Rev Mol Cell Biol 16:727-741. https:// doi.org/10.1038/nrm4085

Boyes DC, Zayed AM, Ascenzi R, McCaskill AJ, Hoffman NE, Davis KR, Görlach J (2001) Growth stage-based phenotypic analysis of Arabidopsis. Plant Cell 13(7):1499-1510
Cambiagno DA, Nota F, Zavallo D, Rius S, Casati P, Asurmendi S, Alvarez ME (2018) Immune receptor genes and pericentromeric transposons as targets of common epigenetic regulatory elements. Plant J 96:1178-1190. https://doi.org/10.1111/tpj.14098

Castel SE, Martienssen RA (2013) RNA interference (RNAi) in the Nucleus: roles for small RNA in transcription, epigenetics and beyond. Nat Rev Genet 23:1-7. https://doi.org/10.1038/ jid.2014.371

Conti G, Rodriguez MC, Venturuzzi AL, Asurmendi S (2017a) Modulation of host plant immunity by Tobamovirus proteins. Ann Bot 119:737-747. https://doi.org/10.1093/aob/mcw216

Conti G, Zavallo D, Venturuzzi AL, Rodriguez MC, Crespi M, Asurmendi S (2017b) TMV induces RNA decay pathways to modulate gene silencing and disease symptoms. Plant J 89:73-84. https:// doi.org/10.1111/tpj.13323

Cuerda-Gil D, Slotkin RK (2016) Non-canonical RNA-directed DNA methylation. Nat Plants. https://doi.org/10.1038/nplants.2016.163

Dardick C (2007) Comparative expression profiling of Nicotiana benthamiana leaves systemically infected with three fruit tree viruses. Mol Plant Microbe Interact 20:1004-1017. https://doi. org/10.1094/MPMI-20-8-1004

Dastogeer KMG, Li H, Sivasithamparam K, Jones MGK, Wylie SJ (2018) Fungal endophytes and a virus confer drought tolerance to Nicotiana benthamiana plants through modulating osmolytes, antioxidant enzymes and expression of host drought responsive genes. Environ Exp Bot 149:95-108. https://doi.org/10.1016/j. envexpbot.2018.02.009

Diezma-Navas L, Pérez-González A, Artaza H, Alonso L, Caro E, Llave C, Ruiz-Ferrer V (2019) Crosstalk between epigenetic silencing and infection by tobacco rattle virus in Arabidopsis. Mol Plant Pathol. https://doi.org/10.1111/mpp.12850

Dowen RH, Pelizzola M, Schmitz RJ, Lister R, Dowen JM, Nery JR, Dixon JE, Ecker JR (2012) Widespread dynamic DNA methylation in response to biotic stress. Proc Natl Acad Sci USA. https:// doi.org/10.1073/pnas.1209329109

Gagliardi D, Cambiagno DA, Arce AL, Tomassi AH, Giacomelli JI, Ariel FD, Manavella PA (2019) Dynamic regulation of chromatin topology and transcription by inverted repeat-derived small RNAs in sunflower. Proc Natl Acad Sci USA 116:17578-17583. https:// doi.org/10.1073/pnas.1903131116

Gallego-Bartolomé J, Liu W, Kuo PH, Feng S, Ghoshal B, Gardiner J, Zhao JMC, Park SY, Chory J, Jacobsen SE (2019) Co-targeting RNA polymerases IV and V promotes efficient de novo DNA methylation in Arabidopsis. Cell 176:1068-1082.e19. https://doi. org/10.1016/j.cell.2019.01.029

Guo X, Ma Z, Zhang Z, Cheng L, Zhang X, Li T (2017) Small RNAsequencing links physiological changes and RdDM process to vegetative-to-floral transition in apple. Front Plant Sci 8:1-15. https://doi.org/10.3389/fpls.2017.00873

Haag JR, Ream TS, Marasco M, Nicora CD, Norbeck AD, Pasa-Tolic L, Pikaard CS (2012) In vitro transcription activities of Pol IV, Pol V, and RDR2 reveal coupling of Pol IV and RDR2 for dsRNA synthesis in plant RNA silencing. Mol Cell 48:811-818. https:// doi.org/10.1016/j.molcel.2012.09.027

Hamera S, Song X, Su L, Chen X, Fang R (2012) Cucumber mosaic virus suppressor $2 \mathrm{~b}$ binds to AGO4-related small RNAs and impairs AGO4 activities. Plant J 69:104-115. https://doi. org/10.1111/j.1365-313X.2011.04774.x

Harris CJ, Scheibe M, Wongpalee SP, Liu W, Cornett EM, Vaughan RM, Li X, Chen W, Xue Y, Zhong Z, Yen L, Barshop WD, Rayatpisheh S, Gallego-Bartolome J, Groth M, Wang Z, Wohlschlegel JA, Du J, Rothbart SB, Butter F, Jacobsen SE (2018) A DNA methylation reader complex that enhances gene transcription. Science (80- ) 362:1182-1186 . https://doi.org/10.1126/ science.aar7854 
Havaux M (2014) Carotenoid oxidation products as stress signals in plants. Plant J 79:597-606. https://doi.org/10.1111/tpj.12386

Havecker ER, Wallbridge LM, Hardcastle TJ, Bush MS, Kelly KA, Dunn RM, Schwach F, Doonan JH, Baulcombe DC (2010) The arabidopsis RNA-directed DNA methylation argonautes functionally diverge based on their expression and interaction with target loci. Plant Cell 22:321-334. https://doi.org/10.1105/ tpc.109.072199

He XJ, Ma ZY, Liu ZW (2014) Non-coding RNA transcription and RNA-directed DNA methylation in arabidopsis. Mol Plant 7:1406-1414. https://doi.org/10.1093/mp/ssu075

Huang J, Yang M, Lu L, Zhang X (2016) Diverse functions of small RNAs in different plant-pathogen communications. Front Microbiol 7:1-17. https://doi.org/10.3389/fmicb.2016.01552

Ibdah M, Dubey NK, Eizenberg H, Dabour Z, Abu-Nassar J, Gal-On A, Aly R (2014) Cucumber Mosaic Virus as a carotenoid inhibitor reducing Phelipanche aegyptiaca infection in tobacco plants. Plant Signal Behav 9:1-6. https://doi.org/10.4161/psb.32096

Inaba JI, Kim BM, Shimura H, Masuta C (2011) Virus-induced necrosis is a consequence of direct protein-protein interaction between a viral RNA-silencing suppressor and a host catalase. Plant Physiol 156:2026-2036. https://doi.org/10.1104/ pp. 111.180042

Ismayil A, Haxim Y, Wang Y, Li H, Qian L, Han T, Chen T, Jia Q, Yihao Liu A, Zhu S, Deng H, Gorovits R, Hong Y, HanleyBowdoin L, Liu Y (2018) Cotton Leaf Curl Multan virus C4 protein suppresses both transcriptional and post-transcriptional gene silencing by interacting with SAM synthetase. PLoS Pathog 14:1-24. https://doi.org/10.1371/journal.ppat.1007282

Jay F, Wang Y, Yu A, Taconnat L, Pelletier S, Colot V, Renou JP, Voinnet O (2011) Misregulation of AUXIN RESPONSE FACTOR 8 underlies the developmental abnormalities caused by three distinct viral silencing suppressors in Arabidopsis. PLoS Pathog. https:// doi.org/10.1371/journal.ppat.1002035

Johnson N, Yeoh J, Coruh C, Axtell M (2016) Shortstack Version 3.x. G3 6:2103-2111

Karolchik D, Baertsch R, Diekhans M, Furey TS, Hinrichs A, Lu YT, Roskin KM, Schwartz M, Sugnet CW, Thomas DJ, Weber RJ, Haussler D, Kent WJ (2003) The UCSC Genome Browser Database. Nucleic Acids Res 31:51-54. https://doi.org/10.1093/nar/ gkg129

Kawakatsu T, Huang SC, Jupe F, Sasaki ER, Schmitz J, Urich MA, Castanon R, Nery JR, Barragan C, He Y, Chen H, Dubin M, Lee C-R, Wang C, Bemm F, Becker C, O'Neil R, O'Malley RC, Quarless DX, Schork NJ, Weigel D, Nordborg M, Ecker R (2016) Epigenomic diversity in a global collection of Arabidopsis thaliana accessions. Cell 166:492-505

Khanna-Chopra R (2012) Leaf senescence and abiotic stresses share reactive oxygen species-mediated chloroplast degradation. Protoplasma 249:469-481. https://doi.org/10.1007/s00709-011-0308-z

Kørner CJ, Pitzalis N, Peña EJ, Erhardt M, Vazquez F, Heinlein M (2018) Crosstalk between PTGS and TGS pathways in natural antiviral immunity and disease recovery. Nat Plants 4:157-164. https://doi.org/10.1038/s41477-018-0117-x

Landi M, Tattini M, Gould KS (2015) Multiple functional roles of anthocyanins in plant-environment interactions. Environ Exp Bot 119:4-17. https://doi.org/10.1016/j.envexpbot.2015.05.012

Law JA, Jacobsen SE (2010) Establishing, maintaining and modifying DNA methylation patterns in plants and animals. Nat Rev Genet 11:204-220. https://doi.org/10.1038/nrg2719

Le TN, Schumann U, Smith NA, Tiwari S, Khang Au PC, Zhu QH, Taylor JM, Kazan K, Llewellyn DJ, Zhang R, Dennis ES, Wang MB (2014) DNA demethylases target promoter transposable elements to positively regulate stress responsive genes in Arabidopsis. Genome Biol 15:1-18. https://doi.org/10.1186/s1305 9-014-0458-3
Lei M, Zhang H, Julian R, Tang K, Xie S, Zhu JK (2015) Regulatory link between DNA methylation and active demethylation in Arabidopsis. Proc Natl Acad Sci USA 112:3553-3557. https://doi. org/10.1073/pnas.1502279112

Leone M, Keller MM, Cerrudo I, Ballaré CL (2014) To grow or defend? Low red: far-red ratios reduce jasmonate sensitivity in Arabidopsis seedlings by promoting DELLA degradation and increasing JAZ10 stability. New Phytol 204(2):355-367

Leon-Reyes A, Van der Does D, De Lange ES, Delker C, Wasternack C, Van Wees SCM, Ritsema T, Pieterse CMJ (2010) Salicylatemediated suppression of jasmonate-responsive gene expression in arabidopsis is targeted downstream of the jasmonate biosynthesis pathway. Planta 232:1423-1432. https://doi.org/10.1007/ s00425-010-1265-Z

Li X, Zhu J, Hu F, Ge S, Ye M, Xiang H, Zhang G, Zheng X, Zhang H, Zhang S, Li Q, Luo R, Yu C, Yu J, Sun J, Zou X, Cao X, Xie X, Wang J, Wang W (2012) Single-base resolution maps of cultivated and wild rice methylomes and regulatory roles of DNA methylation in plant gene expression. BMC Genomics 13:1-15. https:// doi.org/10.1186/1471-2164-13-300

Li Y, Cui H, Cui X, Wang A (2016) The altered photosynthetic machinery during compatible virus infection. Curr Opin Virol 17:19-24. https://doi.org/10.1016/j.coviro.2015.11.002

Liang L, Chang Y, Lu J, Wu X, Liu Q, Zhang W, Su X, Zhang B (2019) Global methylomic and transcriptomic analyses reveal the broad participation of DNA methylation in daily gene expression regulation of Populus trichocarpa. Front Plant Sci 10:1-10. https://doi. org/10.3389/fpls.2019.00243

Liu Y, Tikunov Y, Schouten RE, Marcelis LFM, Visser RGF, Bovy A (2018) Anthocyanin biosynthesis and degradation mechanisms in Solanaceous vegetables: a review. Front Chem. https://doi. org/10.3389/fchem.2018.00052

Livak KJ, Schmittgen TD (2001) Analysis of relative gene expression data using real-time quantitative PCR and the $2^{-\Delta \Delta \mathrm{C}_{\mathrm{T}}}$ method. Methods 25(4):402-408

López A, Ramírez V, García-Andrade J, Flors V, Vera P (2011) The RNA silencing enzyme RNA polymerase $\mathrm{V}$ is required for plant immunity. PLoS Genet. https://doi.org/10.1371/journ al.pgen. 1002434

Martínez de Alba A, Moreno A, Gabriel M, Mallory AC, Christ A, Bounon R, Balzergue S, Aubourg S, Gautheret D, Crespi M, Vaucheret H, Maizel A (2015) In plants, decapping prevents RDR6-dependent production of small interfering RNAs from endogenous mRNAs. Nucleic Acids Res 43:2902-2913. https:// doi.org/10.1093/nar/gkv119

Mazid M, Khan TA, Mohammad F (2011) Role of secondary metabolites in defense mechanisms of plants. Biol Med 3:232-249

Mette MF, Aufsatz W, Van Der WJ, Matzke MA, Matzke AJM (2000) Transcriptional silencing and promoter DNA methylation inhibits transcription in plants. EMBO J 19:8

Minerva S. Trejo-Arellano M, Mehdi S, de Jonge J, DvorákTomastíková E, Köhler C, Hennig L (2019) Dark-induced senescence causes localized changes in DNA methylation. Plant Physiol. https ://doi.org/10.1104/pp.108.131805

Moeder W, Del Pozo O, Navarre DA, Martin GB, Klessig DF (2007) Aconitase plays a role in regulating resistance to oxidative stress and cell death in Arabidopsis and Nicotiana benthamiana. Plant Mol Biol 63:273-287. https://doi.org/10.1007/s11103-006-9087-x

Nicaise V (2014) Crop immunity against viruses: Outcomes and future challenges. Front Plant Sci 5:1-18. https://doi.org/10.3389/ fpls.2014.00660

Niehl A, Heinlein M (2019) Perception of double-stranded RNA in plant antiviral immunity. Mol Plant Pathol 20:1203-1210. https ://doi.org/10.1111/mpp.12798 
Niehl A, Wyrsch I, Boller T, Heinlein M (2016) Double-stranded RNAs induce a pattern-triggered immune signaling pathway in plants. New Phytol 211:1008-1019. https://doi.org/10.1111/nph.13944

Pallas V, García JA (2011) How do plant viruses induce disease? Interactions and interference with host components. J Gen Virol 92:2691-2705. https://doi.org/10.1099/vir.0.034603-0

Popova OV, Dinh HQ, Aufsatz W, Jonak C (2013) The RdDM pathway is required for basal heat tolerance in arabidopsis. Mol Plant 6:396-410. https://doi.org/10.1093/mp/sst023

Přibylová A, Čermák V, Tyč D, Fischer L (2019) Detailed insight into the dynamics of the initial phases of de novo RNA-directed DNA methylation in plant cells. Epigenet Chromatin 12:1-14. https:// doi.org/10.1186/s13072-019-0299-0

Pružinská A, Tanner G, Aubry S, Anders I, Moser S, Müller T, Ongania KH, Kräutler B, Youn JY, Liljegren SJ, Hörtensteiner S (2005) Chlorophyll breakdown in senescent Arabidopsis leaves. Characterization of chlorophyll catabolites and of chlorophyll catabolic enzymes involved in the degreening reaction. Plant Physiol 139:52-63. https://doi.org/10.1104/pp.105.065870

Rabino I, Mancinelli AL (1986) Light, temperature, and anthocyanin production. Plant Physiol 81(3):922-924

Ruijter JM, Ramakers C, Hoogaars WMH, Karlen Y, Bakker O, van den Hoff MJB, Moorman AFM (2009) Amplification efficiency: linking baseline and bias in the analysis of quantitative PCR data. Nucleic Acids Res 37(6):e45-e45

Shaw JG (1999) Tobacco mosaic virus and the study of early events in virus infections. Philos Trans R Soc B 354:603-611. https://doi. org/10.1098/rstb.1999.0412

Shimura H, Pantaleo V, Ishihara T, Myojo N, Inaba J, Sueda K, Burgyán J, Masuta C (2011) A Viral Satellite RNA Induces Yellow Symptoms on Tobacco By Targeting a Gene Involved in Chlorophyll Biosynthesis Using the RNA Silencing Machinery. PLoS Pathog 7:1-12. https://doi.org/10.1371/journal.ppat.1002021

Smith NA, Eamens AL, Wang MB (2011) Viral small interfering RNAs target host genes to mediate disease symptoms in plants. PLoS Pathog 7:1-9. https://doi.org/10.1371/journal.ppat.1002022

Stroud H, Greenberg MVC, Feng S, Bernatavichute YV, Jacobsen SE (2013) Comprehensive analysis of silencing mutants reveals complex regulation of the Arabidopsis methylome. Cell 152:352-364. https://doi.org/10.1016/j.cell.2012.10.054

Sun Y, Fan M, He Y (2019) DNA methylation analysis of the Citrullus lanatus response to cucumber green mottle mosaic virus infection by whole-genome bisulfite sequencing. Genes (Basel) 10:344. https://doi.org/10.3390/genes10050344

To TK, Saze H, Kakutani T (2015) DNA methylation within transcribed regions. Plant Physiol 168:1219-1225. https://doi. org/10.1104/pp.15.00543

Underwood CJ, Henderson IR, Martienssen RA (2017) Genetic and epigenetic variation of transposable elements in Arabidopsis. Curr Opin Plant Biol 36:135-141
Vance V, Vaucheret H (2001) RNA silencing in plants-defense and counterdefense. Science (80- ) 292:2277-2280. https://doi. org/10.1126/science.1061334

Wang MB, Masuta C, Smith NA, Shimura H (2012) RNA silencing and plant viral diseases. Mol Plant Microbe Interact 25:1275-1285. https://doi.org/10.1094/MPMI-04-12-0093-CR

Westwood JH, Mccann L, Naish M, Dixon H, Murphy AM, Stancombe MA, Bennett MH, Powell G, Webb AAR, Carr JP (2013) A viral RNA silencing suppressor interferes with abscisic acidmediated signalling and induces drought tolerance in Arabidopsis thaliana. Mol Plant Pathol 14:158-170. https://doi.org/10.11 11/j.1364-3703.2012.00840.x

Willmann MR, Endres MW, Cook RT, Gregory BD (2011) The functions of RNA-dependent RNA polymerases in Arabidopsis. Arab B 9:e0146. https://doi.org/10.1199/tab.0146

Xiao S, Ellwood S, Findlay K, Oliver RP, Turner JG (1997) Characterization of three loci controlling resistance of Arabidopsis thaliana accession Ms-0 to two powdery mildew diseases. Plant J 12:757-768. https://doi.org/10.1046/j.1365-313X.1997.12040 757.x

Xie M, Yu B (2015) siRNA-directed DNA Methylation in Plants. 23-31

Yang H, Chang F, You C, Cui J, Zhu G, Wang L, Zheng Y, Qi J, Ma H (2015) Whole-genome DNA methylation patterns and complex associations with gene structure and expression during flower development in Arabidopsis. Plant J 81:268-281. https://doi. org/10.1111/tpj. 12726

Yang T, Wang Y, Teotia S, Wang Z, Shi C, Sun H, Gu Y, Zhang Z, Tang G (2019) The interaction between miR160 and miR165/166 in the control of leaf development and drought tolerance in Arabidopsis. Sci Rep 9:1-13. https://doi.org/10.1038/s41598-019-39397-7

Zavallo D, Debat HJ, Conti G, Manacorda CA, Rodriguez MC, Asurmendi S (2015) Differential mRNA accumulation upon early Arabidopsis thaliana infection with ORMV and TMV-Cg is associated with distinct endogenous small RNAs level. PLoS ONE 10:1-24. https://doi.org/10.1371/journal.pone.0134719

Zhong X, Hale CJ, Law JA, Johnson LM, Feng S, Tu A, Jacobsen SE, Angeles L, Curriculum SC, Angeles L, Angeles L, Angeles CL, Angeles L (2013) DDR complex facilitates global association of RNA Polymerase V to promoters and evolutionarily young transposons. Nat Struct Mol Biol 19:870-875. https://doi.org/10.1038/ nsmb.2354.DDR

Publisher's Note Springer Nature remains neutral with regard to jurisdictional claims in published maps and institutional affiliations. 